T. 2, № 2, 2020

УДК 623.41, 623.419

Я. С. Паранчук

Національний університет «Львівська політехніка», кафедра електромехатроніки та комп’ютеризованих електромеханічних систем”, yparanchuk@yahoo.com

В. Б. Цяпа

Національний університет «Львівська політехніка», кафедра електромехатроніки та комп’ютеризованих електромеханічних систем”, volodymyr.b.tsiapa@1pnu.ua

Д. Г. Гордус

Національний університет «Львівська політехніка», кафедра електромехатроніки та комп’ютеризованих електромеханічних систем”, sharaitara@gmail.com

\title{
АНАЛІЗ ДИНАМІКИ РУХУ ЕЛЕКТРОДІВ ДУГОВОЇ СТАЛЕПЛАВИЛЬНОЇ ПЕЧІ ЗА РІЗНИХ ЗАКОНІВ КЕРУВАННЯ
}

https://doi.org/

(С Паранчук Я. С., Цяпа В. Б., Гордус Д. Г., 2020

Дугові сталеплавильні печі (ДСП) - це основні електротехнологічні агрегати для виробництва високолегованих та спеціальних сталей і прецизійних сплавів. Ефективність їх роботи визначається досконалістю підсистеми керування електричним режимом (ЕР) та підсистеми регулювання його координат. Вказані підсистеми складають структуру ісрархічної системи керування режимами електросталеплавлення, яка належить до класу складних взаємозв'язаних суттєво нелінійних стохастичних систем з інтенсивними параметричними і координатними збуреннями та пофазно несиметричним навантаженням.

Розглянуто питання аналізу показників динаміки руху електродів у процесі відпрацювання детермінованих збурень при реалізації різних моделей синтезу сигналу керування на переміщення електродів. Ця задача с складовою при розв'язанні комплексної проблеми синтезу адаптивного оптимального керування режимами електросталеплавлення за показниками електротехнологічної ефективності ДСП та електромагнітної сумісності їі режимів $з$ електромережею. Показники динаміки досліджено за складеною трифазною у миттєвих координатах структурою Simulink-моделлю при варіації законів формування сигнала розузгодження ЕР та параметрів підсистеми регулювання положення електродів.

Отримано часові залежності зміни координат ЕР та підсистеми регулювання довжин дуг i виконано їх аналіз. Обгрунтовано вектор варіативних параметрів та моделей законів формування сигналу розузгодження ЕР, який доцільно покласти в основу при проектуванні директивних графіків плавлення сталей на цій ДСП. 
Проаналізовано отримані оцінки чутливості показників динаміки руху електродів до коефіціснта підсилення підсистеми регулювання положення електродів та диференційного i напругового законів формування сигналу розузгодження ЕР. Обгрунтовано позитивні властивості напругового закону формування сигналу розузгодження, зокрема, проілюстровано значно вищу його пофазну автономність регулювання координат ЕР порівняно $з$ диференційною моделлю, якій властива вища за інших рівних умов коливність реакції системи на дію детермінованих збурень та пофазна взаємозв'язаність процесу регулювання ЕР.

Ключові слова: дугова сталеплавильна піч, закон керування, швидкодія, перегулювання, пофазна автономність.

\section{Постановка проблеми}

Сьогодні металургійних підприємствах неухильно зростає частка виробництва сталі в дугових сталеплавильних печах (ДСП) [1]. Як електротехнологічним агрегатам, їм властива вища електрична ефективність та екологічність порівняно з конверторами та мартенами. В ДСП виплавляється основна частина високоякісних легованих сталей та прицезійних сплавів, виплавляння яких у мартенівських чи конвертерних печах $є$ неможливим чи проблематичним.

Сьогодні експлуатуються ДСП місткістю від 0,1 до 100 тонн. Потужність пічних трансформаторів становить від одного до 300 МВА (ДСП-250) і вище, а питома потужність силового електрообладнання зросла до 1,2 MBА/т. Для покращення показників електромагнітної сумісності потужні ДСП комплектуються статичними тиристорними компенсаторами, встановлена потужність яких сягає 330МВАР, а для отримання вищої енерготехнологічної ефективності на ДСП використовуються новітні технології плавлення, зокрема, що реалізуються в установках «піч-ківш». 3 цією метою в дугових печах, особливо в потужних, використовують технології (директивні графіки) плавлення, які характеризуються значною інтенсифікацією електричного режиму: плавлення шихти ведуть на довгих дугах (вищих напругах на дугах) і знижених струмах, що вимагає встановлення пічних трансформаторів з вищими вторинними напругами на різних ступенях трансформації [2-4].

Зважаючи на вказаний діапазон потужностей силового електрообладнання та характеристики режимів, а також у багатьох випадках, через обмеження пропускної здатності ліній електропередач, актуальним при формуванні електричних режимів плавлення є обмеження граничних (максимальних) значень потужності та стратегії керування ЕР за критеріями мінімізації питомих витрат електроенергії та мінімізації дисперсії струмів дуг.

\section{Аналіз відомих рішень}

Вказані вище особливості та обмеження при формуванні електричних режимів висувають відповідні вимоги до систем автоматичного керування (САК) (регуляторів потужності дуг) та систем автоматичного регулювання (САР) довжини дуг. Зокрема, актуальною вимога ефективного розширення функціональних можливостей з реалізації алгоритмів та моделей оптимального адаптивного керування електричними режимами та комплексного покращення показників статики та динаміки регулювання координат електричного режиму (ЕР).

Актуальним для сучасних печей, особливо в потужних, $є$ алгоритм керування ЕР за критерієм максимізації коефіцієнта зношування футерівки на етапі основного розплавлювання шихти, що забезпечує максимальне значення електричного коефіцієнта корисної дії печі і максимальну випромінювальну властивість дуг; керування за критерієм максимізації потужності дуг на технологічній стадії окислювання та нагрівання розплаву (максимізація коефіцієнта інтенсивності нагрівання); керування за критерієм максимізації потужності дуг на стадії запалювання дуг і початку проплавлювання колодязів, а також вказаний вище алгоритм керування, що виключає режими перевищення потужності дуг гранично допустимого значення [5-7].

Описані вище вимоги та алгоритми адаптивного оптимального керування можуть бути реалізовані повною мірою за умови досконалої роботи системи регулювання довжини дуг (регулювання 
положення електродів) - локальної підсистеми в структурі ієрархічної дворівневої системи керування ЕР ДСП. Основними вимогами до цієї підсистеми є висока швидкодія регулювання координат за дотримання оптимальних законів руху електродів, зокрема за відпрацювання детермінованих (зокрема екстремальних) збурень ЕР, що трансформується у мінімізацію дисперсії координат ЕР під час відпрацювання випадкових збурень - тобто у якісну стабілізацію координат ЕР на рівні заданих, зокрема оптимальних значень (уставок) регулятора потужності дуг.

Своєю чергою, якісна стабілізація координат електричних режимів на рівні заданих значень, що задаються підсистемою верхнього рівня, додатково підвищує ефективність адаптивного оптимального керування за вказаними вище критеріями.

\section{Обгрунтування напряму дослідження}

Сучасні ДСП комплектуються системами регулювання положення електродів, які відрізняються за системотехнікою (алгоритмами, законами формування сигналу керування на переміщення електродів). Сьогодні на старих печах функціонують САР довжини дуг, що використовують диференційний, напруговий чи струмовий закони керування (моделі формування сигналів формування керування на переміщення електродів). На нових ДСП використовують системи регулювання типу ARCOS, HIREG, Simelt тощо, застосовують модифікації вказаних вище законів або принципово інші закони керування. Системотехніка вказаних законів містить модель формування сигналу розузгодження ЕР та модель формування на його основі сигналу керування на переміщення електродів. Математичні залежності та параметри моделей цих законів $€$ варіативними параметрами при синтезі оптимальних законів руху електродів $\mathrm{i}$, як результат, подають розв'язок оптимізаційної задачі мінімізації дисперсії координат електричного режиму, зокрема дисперсії струмів дуг.

Метою статті є дослідження та порівняльний аналіз показників динаміки руху електродів при відпрацюванні детермінованих збурень для різних моделей формування сигналів керування на переміщення електродів у кожній фазі.

Новизною дослідження є рекомендації з вибору моделі формування сигналу керування на переміщення електродів ДСП за поставленими критеріями оптимальності.

\section{Результати дослідження}

Як сказано вище, отримання оптимальних параметрів моделі закону формування сигналу керування на переміщення електродів визначально впливає на ефективність функціонування ДСП за різними критеріями оптимальності. Узгодження статичної характеристики САР та моделі форму-

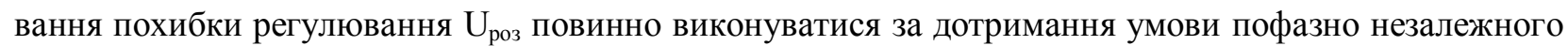
регулювання струмів дуг та потужності дугової печі без відчутного впливу на це навантаження однієї фази на іншу.

Типові (серійні) регулятори потужності дуг, як правило, виконують із нелінійною статичною характеристикою САР ЕР, варіативними параметрами якої $є$ зона нечутливості $\pm \delta$, уставки на граничні швидкості $\pm \delta$ двигуна $\pm \omega_{\max }$ механізму переміщення електродів для обох напрямів руху та коефіцієнта підсилення $k_{p}\left(U_{\text {роз }}\right)$ регулятора потужності на ділянках плавного регулювання сигналу керування $\mathrm{U}_{\mathrm{k}}$ на переміщення електродів [6]. Значення коефіцієнтів підсилення для кожної зони регулювання не $\epsilon$ сталими і змінюються відповідно до зміни ступеня пічного трансформатора $\mathrm{i}$ вибору іншої робочої уставки ЕР.

Нелінійні властивості статичної характеристики регулятора в зоні плавного регулювання диктується необхідністю зміни швидкості реакції системи на різні сигнали похибки регулювання ЕР. Характер нелінійності характеристики у цій зоні є теж варіативним оптимізаційним параметром.

Дослідження показників динаміки при відпрацювання детермінованих збурень виконувалося на трифазній у миттєвих координатах структурній Simulink-моделі силового кола та системи регулювання положення електродів, яка адаптована до параметрів дугової сталеплавильної печі типу ДСП-200 та серійного регулятора потужності дуг типуАРДМ-Т-12, яким комплектується ця піч [8]. 
$\mathrm{y}$ процесі виконання модельних досліджень автори адапували залежність $\mathrm{k}_{\mathrm{p}}\left(\mathrm{U}_{\mathrm{pos}}\right)$ не тільки від зміни ступеня напруги пічного трансформатора, але і від зміни уставки потужності, тобто від положення робочої точки печі на характеристиці $P_{\partial}=f\left(U_{\partial}\right)$. Зрозуміло, що за такого рішення зростає кількість необхідних унікальних характеристик регулятора потужності дуг, які можуть відтворюватися цим регулятором. Вказане ускладнення моделі керування ЕР $є$ певним недоліком, але реалізація цієї функціональної можливості дасть змогу підвищити точність адаптації статичної характеристики регулятора $k_{p}\left(U_{p o s}\right)$ до зміни складових вектора керуючих впливів та до параметрів температурного та фізикохімічного стану шихти чи розплаву, що у результаті, підвищить електротехнологічну ефективність плавлення сталі в ДСП [8]. На рис.1 показано варіанти залежностей статичних нелінійних характеристик регулятора потужності дуг, які реалізовувалися в Simulinkмоделі при дослідженні динаміки регулювання координат ЕР.

Одночасно із зміною регулювальної характеристики регулятора потужності дуг змінювалась також і модель закону формування сигналу розузгодження, тобто досліджувалась ефективність диференційного (1), напругового (2) та струмового (3) законів формування сигналу розузгодження $\mathrm{U}_{\text {роз }}\left(\mathrm{U}_{\partial}, \mathrm{I}_{\partial}\right)$ :

$$
\begin{aligned}
& U_{\text {роз. }}\left(U_{\partial}, I_{\partial}\right)=a U_{\partial}-b I_{\partial} ; \\
& U_{\text {роз. } 2}\left(U_{\partial}, I_{\partial}\right)=k_{u}\left(U_{\partial}-U_{\partial y c m}\right) ; \\
& U_{\text {роз. } 2}\left(U_{\partial}, I_{\partial}\right)=k_{I}\left(I_{\partial}-I_{\partial y c m}\right)
\end{aligned}
$$

де $a, b, k_{u}, k_{I}$ - сталі коефіцієнти, що задають усталений електричний режим роботи ДСП; $U_{\partial}, I_{\partial}-$ поточні діючі значення напруги та струму дуги відповідно; $U_{\partial \text { ycm }} I_{\partial}$ усm - уставки регулятора потужності за напругою та струмом дуг відповідно.

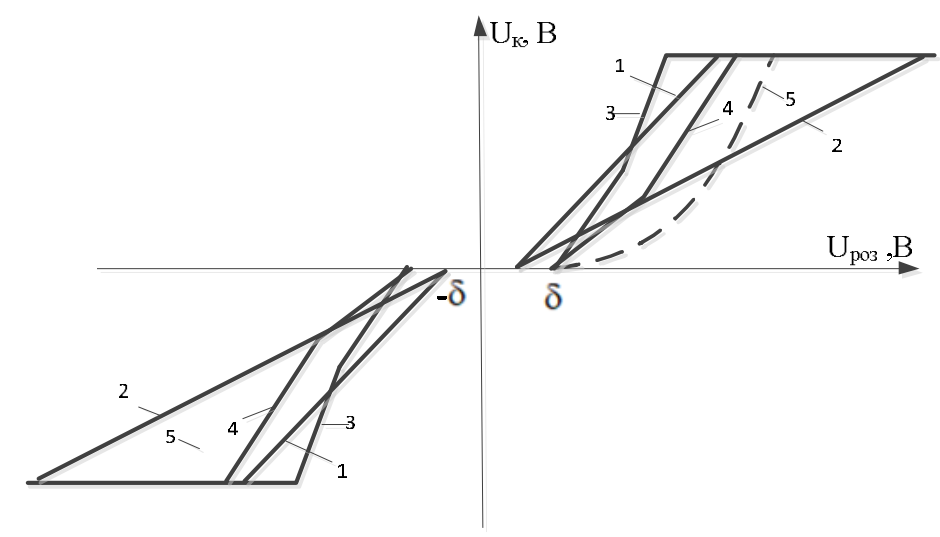

\author{
Рис. 1. Регулювальна \\ характеристика $U_{\kappa}\left(U_{\text {роз }}\right)$ \\ електромеханічного регулятора \\ потужності дуг
}

Комп’ютерні симуляційні дослідження виконували за відпрацювання детермінованих пофазно несиметричних збурень ЕР. При цьому визначали такі показники динаміки реакції системи регулювання довжин дуг на названі збурення, як час регулювання, величина перерегулювання, кількість коливань та інтегральні показники якості.

На рис. 2 та рис. 3 показано отримані на Simulink-моделі часові залежності регулювання напруг $U_{\partial}(t)$ та струмів $I_{\partial}(t)$ дуг (рис. 2 ) та часові залежності сигналів розузгодження $\mathrm{U}_{\text {роз }}(\mathrm{t})$ i швидкості двигунів переміщення електродів $\omega(\mathrm{t})$ (рис. 3) при відпрацюванні послідовності пофазно несиметричних детермінованих (екстремальних) збурень ЕР: обриву дуги у фазі С $(t=0,25 \mathrm{c})$ та експлуатаційного короткого замиканні у фазі А $(t=1,25 \mathrm{c})$ за використання диференційного закону формування сигналу розузгодження $U_{\text {роз }}(t)$ електричного режиму.

Отримані на моделі часові залежності зміни координат ЕР при регулюванні вказаних збурень при коефіцієнті $k=0,5$ регулятора потужності (характеристика 1, рис. 1) показано на рис. $2, a$, pис. 2,6 , рис. $3, a, 6$, а на рис. $2, c$, рис. $2, \partial$, рис. 3 , с, рис. 3 , зображено отримані модельні осцилограм цих самих координат, але при $\mathrm{k}=0,7$ (характеристика 2, рис. 1). 

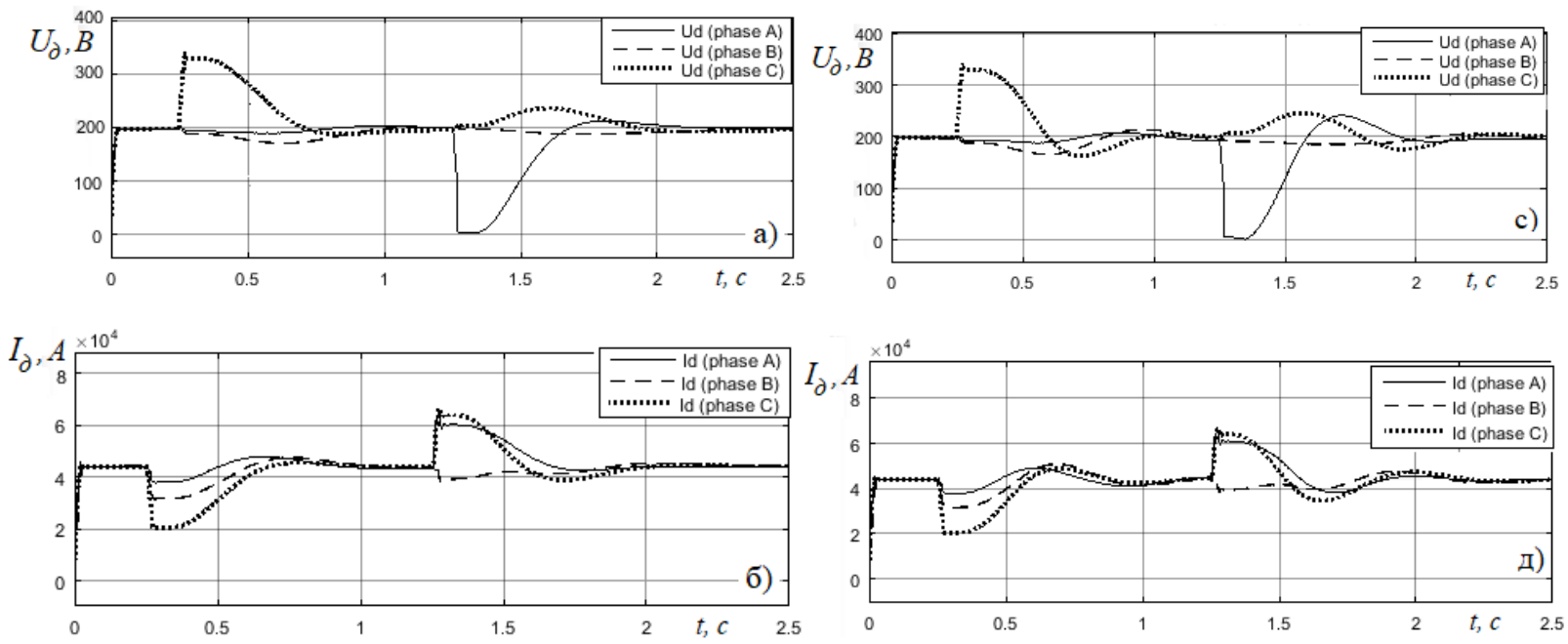

Рис. 2. Часові залежності регулювання напруг $U_{\partial}(t)$ та струмів $I_{\partial}(t)$ дуг при диферениійному законі та $k=0,5$ (а), (б) та при $k=0,7$ (c) та (д) відповідно
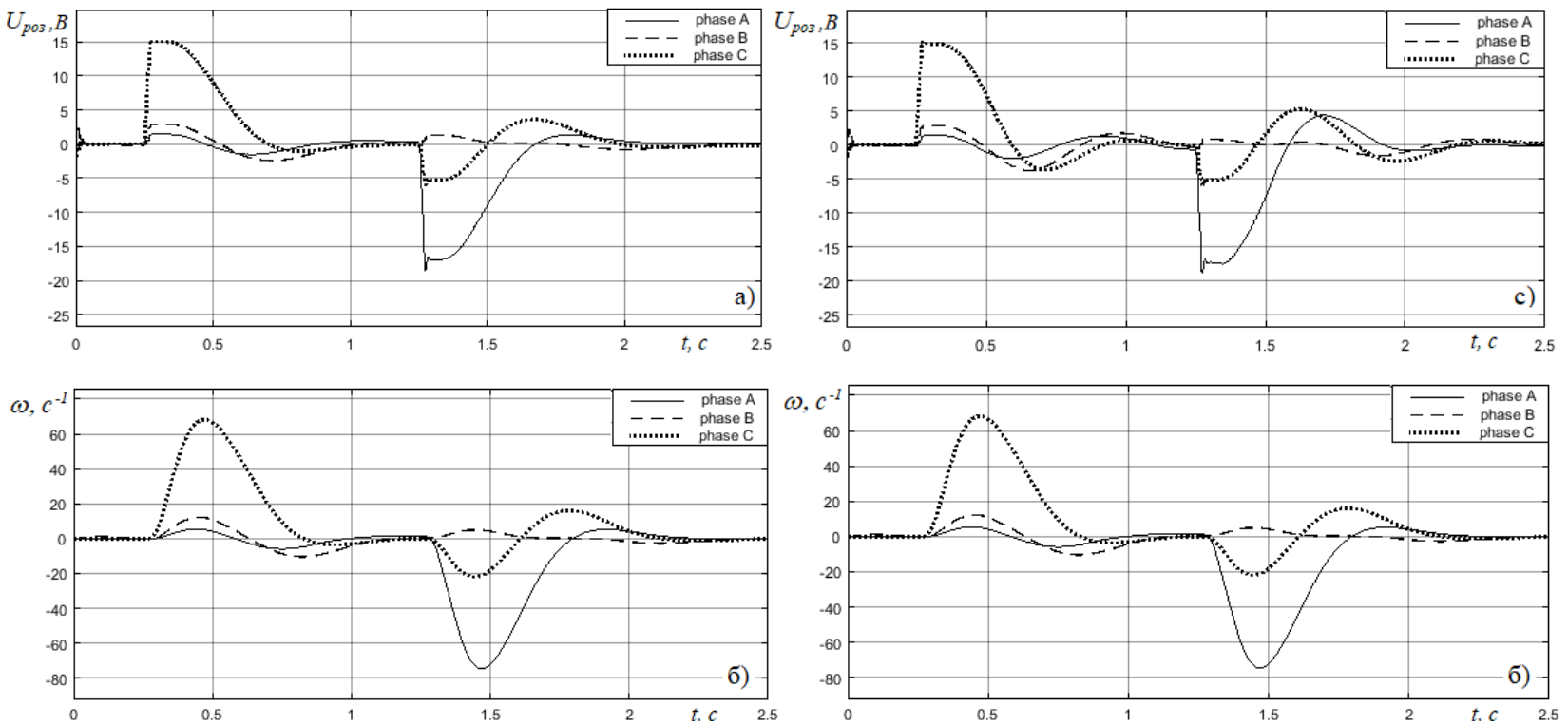

Рис. 3. Часові залежності сигналів розузгодження $U_{\text {роз }}(t)$ та швидкості двигунів $\omega_{\partial}(t)$ переміщення електродів дуг при диференційному законі та $k=0,5$ (а), (б) та при k=0,75 (c) та (д) відповідно

На рис. 4 та рис. 5 показано отримані на комп’ютерній моделі часові залежності цих самих координат регулятора потужності дуг, що і на рис. 2 та на рис. 3, але при використанні напругового закону регулювання, також при $\mathrm{k}=0,5$ (рис. 4 та рис. 5 на частинах (а) та (б)) і при $\mathrm{k}=0,7$ (рис.4 та рис. 5 на частинах (c), та (д)), яким відповідають регулювальні характеристики 1 та 2 регулятора потужності дуг (рис. 1) відповідно.

Отримані часові залежності координат при різних параметрах та характеристиках регулятора потужності дуг ілюструють їх вплив на показники динаміки регулювання детермінованих збурень ЕР.

Якщо порівнювати диференційний та напруговий закони, то за інших рівних умов регулювання збурень за напруговим законом дає високий рівень пофазної автономності їх відпрацювання. Найвиразніше цей факт демонструють часові залежності $\omega(\mathrm{t})$ швидкості двигуна механізму переміщення електродів. Підвищений рівень автономності напругового закону дає змогу зменшити дисперсію координат ЕР, зокрема дисперсію струмів дуг у процесі електросталеплавлення. При роботі на характеристиці 2 регулятора потужності $(\mathrm{k}=0.7)$ зростає швидкодія, проте разом 3 цим 
зростає і коливність. При проектуванні регулятора потужності дуг вказані особливості вимагають прийняття компромісної між швидкодією і коливністю реакції системи на детерміновані пофазно несиметричні збурення ЕР, яка за інших однакових умов визначається значенням коефіцієнта $\mathrm{k}$ регулятора потужності дуг.
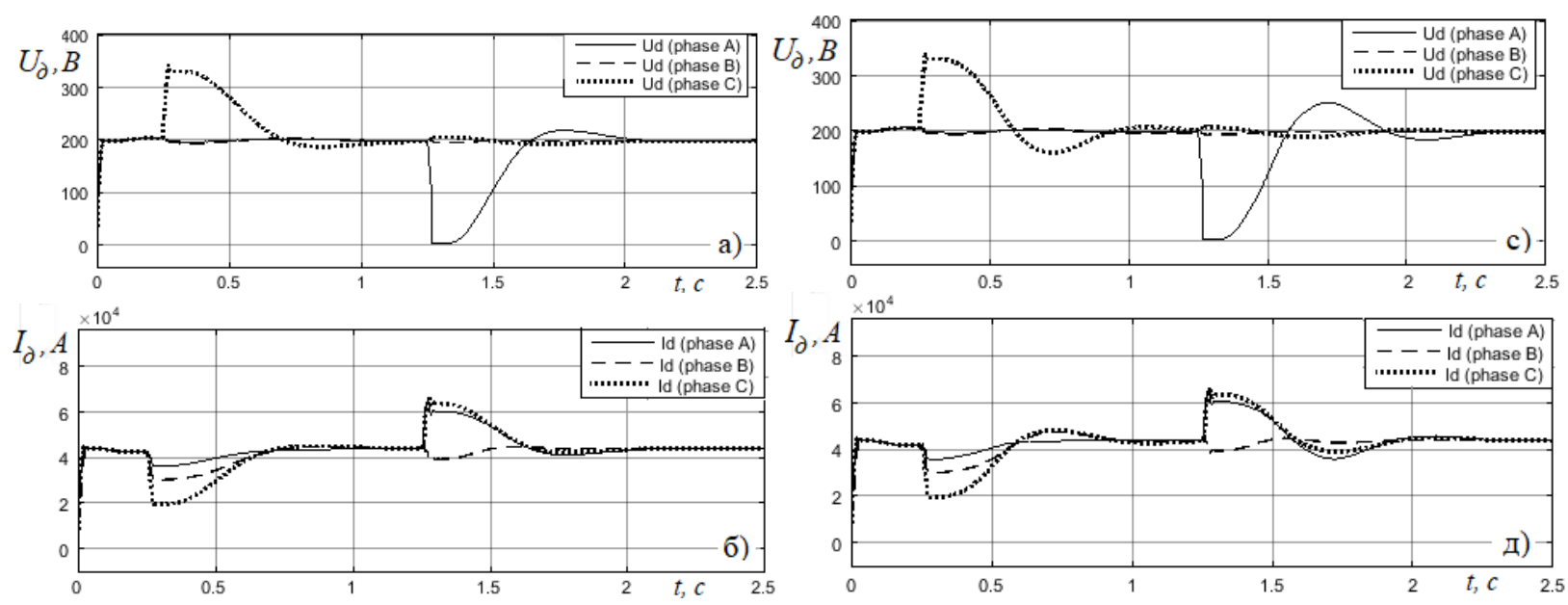

Puс.4. Часові залежності регулювання напруг $U_{\partial}(t)$ та струмів $I_{\partial}(t)$ дуг при напруговому законі та $k=0.5$ (а), (б) та при $k=0.75$ (c) та д) відповідно
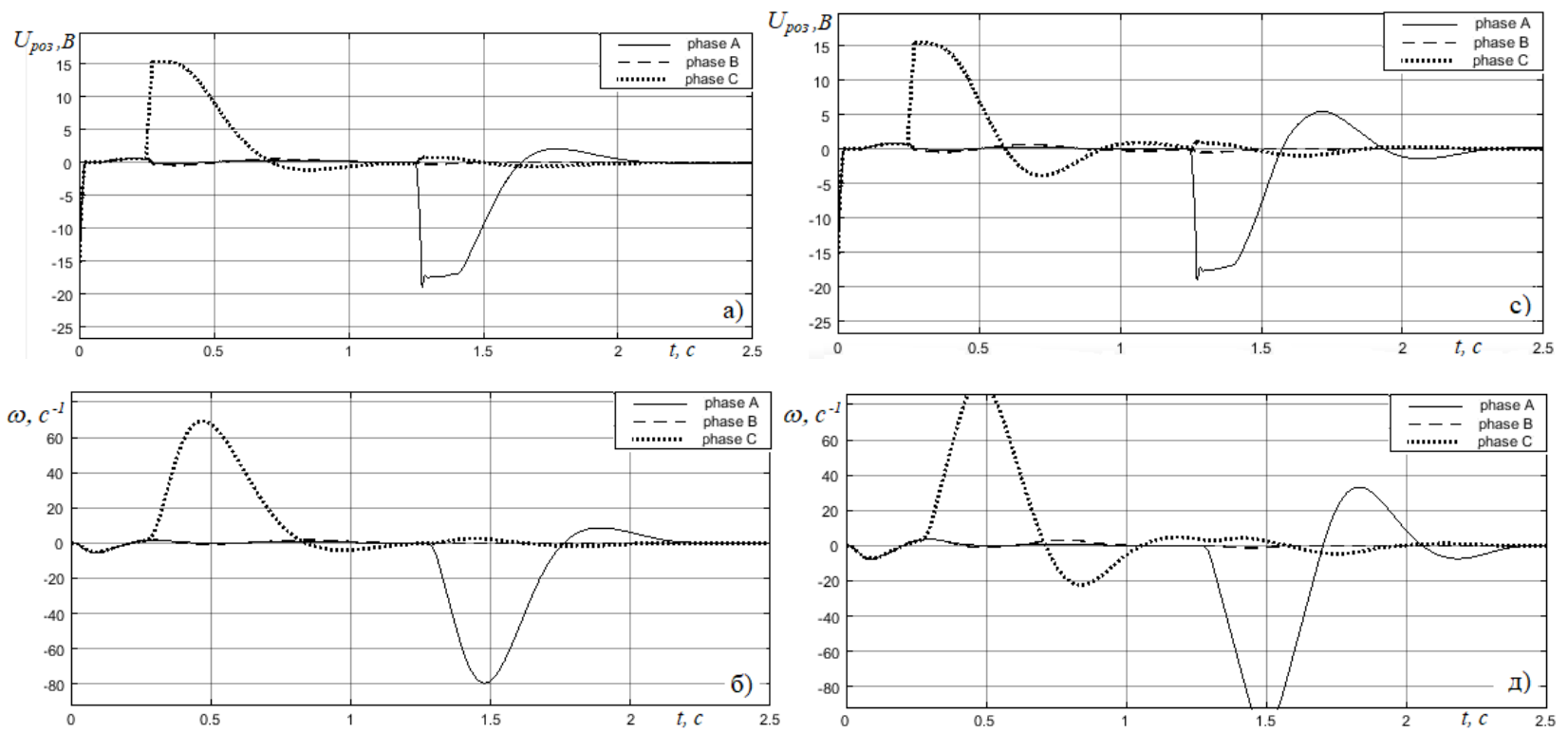

Pис.5. Часові залежності сигналів розузгодження $U_{\text {роз }}(t)$ та швидкості двигунів $\omega_{\partial}(t)$ переміщення електродів дуг при напруговому законі та $k=0.5$ (а), (б) та при $k=0.75$ (c) та (д) відповідно

\section{Висновки}

1. На основі отриманих на Simulink-моделі реакцій системи регулювання положення електродів ДСП проілюстровано вплив на показники динаміки руху електродів напругового та диференційного законів руху електродів: міжфазні взаємовпливи режимів при напруговому законі $\epsilon$ меншими, тобто пофазна автономність регулювання координат ЕР є вищою.

2. При використанні напругового закону формування сигналу керування порівняно 3 диференційним за інших рівних умов час регулювання збурення зменшується га 10-25\%, а при збільшенні коефіцієнта підсилення - зростає коливність системи. 
3. Системотехнічні рішення при проектуванні підсистеми регулювання довжин дуг ДСП повинні прийматися 3 врахуванням компромісу між максимізацією швидкодії та мінімізації коливності реакції системи на детерміновані збурення.

\section{Перспективи подальших досліджень}

Подальші дослідження передбачають дослідження та аналіз впливу інших характеристик та параметрів (зони нечутливості, пружності елементів механізму переміщення електродів, струмового та імпедансного законів) системи регулювання положення електродів (регулятора потужності дуг) на показники динаміки руху електродів дугової сталеплавильної печі та на дисперсію координат ЕР, зокрема на дисперсію струмів дуг при дії детермінованих та випадкових збурень. За цими дослідженнями передбачається отримати оптимальні їх значення, за яких мінімізується дисперсія струмів дуг та покращуються показники динаміки регулювання детермінованих збурень.

\section{Список використаних джерел}

1. http://nashkotel.yu/dugovaya-staleplavilnaya-pech.html

2. Казаков С. В., Гартов В. Восьмая международная конференция по электрометаллургии стали // Электрометаллургия. 2005. № 12. С. 36-43.

3. Кудрин Б. И. Ретроспективные и перспективные взгляды на электропотребление в электрометаллургии // Электрометаллургия. 2003. № 10. С. 2-13.

4. Лопухов Г. А. Состояние и тенденции развития электросталеплавильного производства (по материалам 33 конференции IISI // Электрометаллургия. 2000. № 7. С. 35-37

5. Липшин И. В. Автоматизаиия дуговых печей. М.: Изд-во МГУ, 2004. 167 с.

6. Линнингер А. А., Патучии А. А. Современное технологическое и информаиионное управление на примере конструирования дуговой электропечи // Черные металль. 1995. №3. С. 23-33.

7. Парсункин Б. Н., Андреев С. М., Ахметов У. Б. Оптимизаиия управления технологическими прочессами в металлургии: монграфия. Магнитогорск ГОУ ВПО «МГТУ им. Г.И.Носова», 2006.198 с.

8. Лозинський О. Ю., Паранчук Я. С., Лозинський А. О., Марущак Я. Ю. Математична модель системи живлення та регулювання режимів електротехнологічного комплексу ДСП-ЕПМ // Науковий вісник Наиіонального гірничого університету. 2004. №3. С. 8-15.

1. http://nashkotel.yu/dugovaya-staleplavilnaya-pech.html

\section{References}

2. Kazakov S. V., Hartov V. Vos $\square$ maya mizhnarodna konferentsiya po elektrometallurhiyi stali // Elektrometallurhiya. 2005. No 12. S. 36-43.

3. Kudrin B. Y. Retrospektyvni ta perspektyvni vzhlyady na elektropotreblennya v elektrometallurhiyi // Elektrometallurhiya. 2003. No 10. S. 2-13.

4. Lopukhov H. A. Stan ta tendentsiyi rozvytku elektrostaleplavil $\square$ noho vyrobnytstva (za materialamy 33 konferentsiyi IISI // Elektrometallurhiya. 2000. No 7. S. 35-37

5. Lypshyn Y. V. Avtomatyzatsiya duhovykh pechey. M.: Yzd-vo MHU, 2004. $167 \mathrm{~s}$.

6. Lynnynher A. A. , Patutstsy A. A. Suchasne tekhnolohichne ta informatsiyne upravlinnya na prykladakh konstruyuvannya duhovoyi elektropechi // Chorni metaly. 1995. No 3. S. 23-33.

7. Parsunkyn B. N., Andreev S. M., Akhmetov U. B. Optymizatsiya upravlinnya tekhnolohichnymy protsesamy v metalurhiyi Monhrafiya - Mahnitohors $\square k$ HOU VPO «MHTU im. H. Y. Nosova», 2006. 198 s.

8. Lozyns $\square$ kyy O. Yu., Paranchuk YA. S., Lozyns $\square$ kyy A. O., Marushchak Ya. Yu. Matematychna model $\square$ systemy zhyvlennya ta rehulyuvannya rezhymiv elektrotekhnichnoho kompleksu DSP-EPM // Naukovyy visnyk Natsional $\square$ noho hirnychoho universytetu. 2004. No 3. S. 8-15. 
Аналіз динаміки руху електродів дугової сталеплавильної печі за різних законів керування

Yaroslav Paranchuk

Lviv Polytechnic National University

Department of Electromechatronics and Computerized Electromechanical Systems,

yparanchuk@yahoo.com

V.B.Tsyapa,

Lviv Polytechnic National University,

Department of Electromechatronics and Computerized Electromechanical Systems, volodymyr.b.tsiapa@lpnu.ua

D.Gordus

Lviv Polytechnic National University,

Department of Electromechatronics and Computerized Electromechanical Systems, sharaitara@gmail.com

\section{ANALYSIS OF THE DYNAMICS OF MOVEMENT OF ELECTRODES OF THE ARC STEEL MELTING FURNACE UNDER DIFFERENT LAWS OF CONTROL}

(C) Paranchuk Y. S., Tsyapa V. B., Gordus D. G,2020.

Electric Arc Furnaces (EAF) are the main electrotechnological units that produce high-alloy, special steels and precision alloys. Its efficiency is determined by the impeccable subsystem of the Electrical Mode control (EM) and regulating coordinates of the subsystem. These subsystems constitute the structure of the hierarchical control system of electric steelmaking modes, which belong to a class of complex interconnected nonlinear stochastic systems with intense parametric and coordinate perturbations and phase-asymmetric loading.

In the article, the analyzed movement dynamics indicators of electrodes during deterministic perturbation sequences during implementation of various models of an electrodes movement control signal synthesis. This problem is vital in solving the complex problem of the synthesis of adaptive optimal control of electric steelmaking modes according to the indicators of electrotechnological efficiency of EAF and electromagnetic compatibility of its modes with the electrical grid. Study of the dynamics indicators was performed on a three-phase instantaneous coordinates Simulink computer model of the power supply with variation of the laws of the mismatch-generating signals for the EM and parameters of the electrode position control subsystem.

The article presents the obtained time dependences of the coordinate changes of the EM and the subsystem for adjusting the arc-lengths, and performs their analysis. The vector of variable parameters and law models that determine the mismatch signal of the EM, which is expedient to put in as a basis when designing steps for melting steal on the given EAF, are substantiated. The analysis was performed based on the received estimations of the indicators sensitivity of the dynamics of the electrode movement to gain of a subsystem of electrodes position regulation and differential and voltage laws of the mismatch-generating signals for the EM. The positive properties of the voltage law of the mismatchgenerating signals is substantiated, in particular, its much higher phase-by-phase autonomy of the EM coordinate regulation is illustrated in comparison with the differential model.

Key words: electric arc furnace, control law, speed, overtraining, phase-by-phase autonomy 